\title{
Rapid analysis of volatile arsenic species released from lake sediment by a packed cotton column coupled with atomic fluorescence spectrometry
}

\author{
Chun-Gang Yuan, ${ }^{a}$ Kegang Zhang, ${ }^{a b}$ Zhenhua Wang ${ }^{b}$ and Guibin Jiang ${ }^{* b}$
}

Received 20th April 2010, Accepted 5th July 2010

DOI: 10.1039/c0ja00005a

It is very important to qualify and quantify volatile arsenic species produced by sediment in order to further understand transformation and transportation of arsenic. Effective separation and sensitive detection of various volatile arsenic species are definitely the key steps for that. In this paper, a short packed cotton column was found effective to separate volatile arsenicals $\left(\mathrm{AsH}_{3}, \mathrm{CH}_{3} \mathrm{AsH}_{2},\left(\mathrm{CH}_{3}\right)_{2} \mathrm{AsH}\right.$ and $\left.\left(\mathrm{CH}_{3}\right)_{3} \mathrm{As}\right)$ rapidly. Based on this, a new online system for collection and speciation of volatile arsenic species was developed. After successful separation on a cotton column, volatile arsenic species were sensitively detected by atomic fluorescence spectrometry (AFS). A special PTFE chamber was designed and applied for both incubation and collection of volatile arsenicals generated from sediment online. Minor amounts of volatile arsenicals produced from sediment in headspace were sensitively measured. Real sample analysis and a spiking experiment indicated that the established system was sensitive and practical for the analysis of volatile arsenicals produced in the environment. It will be a very useful tool for further understanding the transformation of arsenic in the environment with low instrumental costs and running fees.

\section{Introduction}

Arsenic is introduced into the environment primarily from geochemical sources and is further causing global pollutions with subsequent health related issues. It can interact with biota and thus result in arsenic biogeocycling. ${ }^{1,2}$ Recent studies have shown that yeast, bacteria and fungi in the environment are involved in the processes of biotransforming ionic arsenic species into methylated arsenic compounds, ${ }^{3-5}$ especially microorganisms with arsenic resistance genes. ${ }^{6,7}$ An interesting mechanism of bacterial resistance to arsenic is through the release of gaseous arsenic species such as arsine and mono-, di- and trimethylarsine. ${ }^{8-13}$ Gaseous arsines are regarded as the direct evidence of arsenic biomethylation (or detoxification) by microbial activities. ${ }^{14,15}$ On the other hand, studies indicated that the volatilization process is also a potential effective method to remove arsenic from contaminated sites. ${ }^{4}$ Direct measurement of arsenic release is an essential step for the study of arsenic transformation and pollution control.9,16,17

Generally, volatile arsenic species can be separated by gas chromatographic (GC) systems ${ }^{\mathbf{1 1 , 1 8}}$ and detected by inductively coupled plasma mass spectrometry (ICP-MS) or mass spectrometry (MS). ${ }^{19-21}$ Although some methods for volatile arsenic speciation have been reported in the past, new analytical methods for volatile arsenic species in various real samples are still needed for the requirements of sample collection and rapid analysis. Feldmann et al. ${ }^{20,21}$ trapped volatile arsenic compounds in natural gas and the headspace of soils by a chemotrapping

${ }^{a}$ School of Environmental Science \& Engineering, North China Electric Power University, Baoding, 071003, Hebei, P. R. China

${ }^{b}$ State Key Laboratory of Environmental Chemistry and Ecotoxicology, Research Center for Eco-Environmental Sciences, Chinese Academy of Sciences, P. O. Box 2871, Beijing, 100085, P. R. China. E-mail: gbjiang@rcees.ac.cn; Fax: +86-10-62849179; Tel: +86-10-62849334 technique and analyzed them by AFS and ICP-MS. In order to investigate the mechanism of arsenic biotransformation and methylation by bacteria, Qin et al. ${ }^{14}$ trapped the volatile arsenic species released from bacteria culture on $\mathrm{H}_{2} \mathrm{O}_{2}$-impregnated paper and then eluted them with water solution for speciation analysis by LC-ICP-MS. Although the indirect determination of volatile arsenic species was chemically reasonable and reliable, direct quantification and qualification methods are still needed to provide more confident results. Yuan et al. ${ }^{15,22}$ developed a GCICP-MS coupling system recently, which enabled very sensitive direct analysis of volatile arsenic species produced by bacteria culture. Planer-Friedrich et al. ${ }^{11}$ performed speciation of the volatile arsenicals by a solid-phase micro-extraction (SPME) technique with analysis by GC-MS. However, employment of commercial GC and MS increases the cost for analysis and complicates the analytical procedure, which makes it unfeasible for most laboratories. In addition, application of GC-MS to real samples is limited because of its relatively high detection limit. It is necessary to develop more sensitive and practical methods for the direct analysis of volatile arsenic species with low running fees and uncomplicated operation procedures.

In this present paper, it is reported that the volatile arsenic species $\left(\mathrm{AsH}_{3}, \mathrm{CH}_{3} \mathrm{AsH} \mathrm{H}_{2},\left(\mathrm{CH}_{3}\right)_{2} \mathrm{AsH}\right.$ and $\left.\left(\mathrm{CH}_{3}\right)_{3} \mathrm{As}\right)$ were successfully separated by a packed cotton column with a cryogenic trapping technique. By using a specific element detector for arsenic - atomic fluorescence spectrometer (AFS) - instead of ICP-MS, high sensitivity was achieved. There are always a lot of bacteria or other methylation donors in sediment. Quantification and qualification of volatile arsenic species produced by sediment will help us to understand the pollution and self-remediation mechanism of arsenic. In our experiment, one special chamber was designed and applied for both sediment incubation and collection of volatile arsenicals. An online coupling system, which enabled incubation, collection, separation and detection of 
volatile arsenic species released from sediment, was established. Direct and rapid analysis of volatile arsenicals released from sediment was successfully achieved by the coupling system. The results demonstrate that the method is sensitive, reliable and practical for real sample analysis with low instrumental costs and running fees.

\section{Experimental}

\subsection{Chemicals and materials}

Potassium hydroxide (Beijing Chemical Reagents Co., Beijing, China), potassium borohydride (Tianjin Jinke Research Institute for Fine Chemical and Engineering, Tianjin, China), and oxalic acid (Beijing Chemical Reagents Co., Beijing, China) were used for hydride generation reactions. Solutions of arsenite $\left(\mathrm{As}^{\mathrm{III}}\right)$, monomethylarsonic acid $\left(\mathrm{MMA}^{\mathrm{v}}\right)$, dimethylarsinic acid $\left(\mathrm{DMA}^{\mathrm{v}}\right)$, and trimethylarsine oxide (TMAO) standards were prepared as previously described..$^{23,24}$ Volatile arsine standards were generated from these arsenic species. The absorbent cotton was bought from Beijing Medical Apparatus and Instruments Co., Beijing, China.

\subsection{Instrumentations}

An AF-610A atomic fluorescence spectrometer (Beijing Rayleigh Analytical Instrument Co., Beijing, China) was operated with an arsenic hollow cathode lamp. The volatile arsenic species were introduced into the atomizer warmed using infrared radiation and atomized by an argon-hydrogen flame. The instrument was set at $193.7 \mathrm{~nm}$ line source with a hollow cathode lamp operating at $320 \mathrm{~V}$ of PMT voltage. A $60 \mathrm{~mA}$ primary lamp current, $40 \mathrm{~mA}$ assistant lamp current and $500 \mathrm{~mL} \mathrm{~min}^{-1}$ carrier gas were used after optimization. A personal computer fitted with AFS610 software was required to control the AFS instrument and integrate the peak areas in real time.

\subsection{Hydride, standards generation and chamber design}

In our experiment, hydride generation was applied both for standards generation and hydrogen generation. Two peristaltic pumps were applied to pump acidic solution and $\mathrm{KBH}_{4}$ solution for hydride generation. The $10 \% \mathrm{HCl}$ solution was mixed and reacted with $3 \% \mathrm{KBH}_{4}$ (in $0.3 \% \mathrm{KOH}$ ) solution in a T-cross valve to generate hydrogen for the argon-hydrogen flame. The gasliquid mixture was separated by the first gas-liquid separator. After being separated by the second gas-liquid separator, the analytes in the gas phase were carried into the atomizer and detected by AFS. 5\% $\mathrm{H}_{2} \mathrm{C}_{2} \mathrm{O}_{4}(\mathrm{v} / \mathrm{v})$ and $3 \% \mathrm{KBH}_{4}$ (in $0.3 \%$ $\mathrm{KOH}$ ) were mixed and reacted with arsenic standard solution in the customized reaction vessel to generate the volatile arsenic species. The generated volatile arsenic species were carried out by the carrier gas $(\mathrm{He})$. The standards of volatile arsenic species or the analytes in the headspace of samples were mixed with the hydrogen and carrier gas (Ar) of AFS at the second gas-liquid separator. The cotton column, T-cross valve and the gas-liquid separator were connected by a PTFE tube.

To generate arsine standards online, a laboratory-built hydride generation vessel (chamber 7 in Fig. 1) was connected to the incubation vessel. The hydride generation vessel (also made

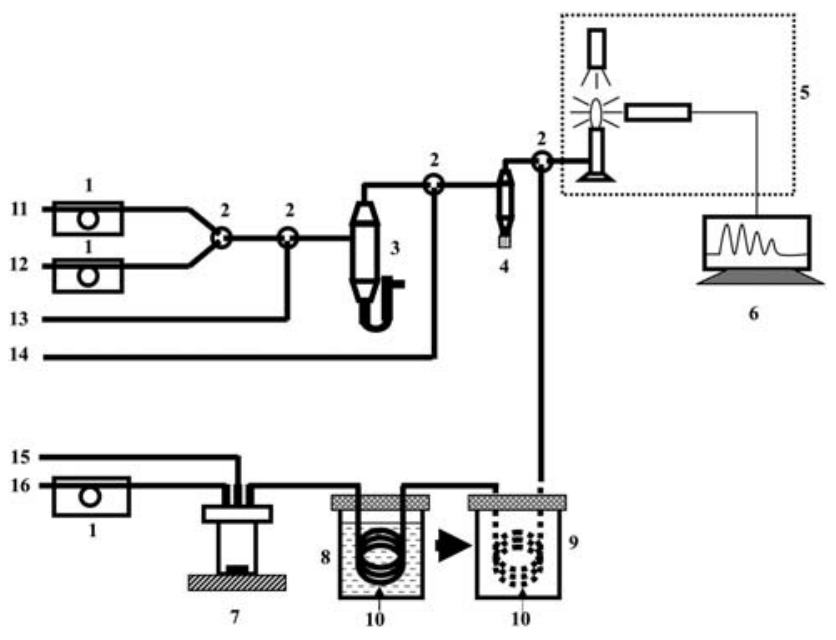

Fig. 1 Sketch of cold trap atomic fluorescence spectrometry coupling system. 1, peristaltic pump; 2, T-connection; 3, liquid-gas separator; 4, second liquid-gas separator; 5, AFS detector; 6, recorder; 7, reaction or incubation vessel; 8, attemperator with liquid nitrogen; 9, attemperator without liquid nitrogen; 10, packed cotton column; 11, $\mathrm{HCl}$ solution; 12, $\mathrm{KBH}_{4}$ solution; 13, carrier gas (Ar); 14, accessorial gas (Ar); 15, carrier gas $(\mathrm{He}) ; 16, \mathrm{KBH}_{4}$ solution.

of Teflon) had a gas inlet (tubing 6, 1/16 i.d.), a gas outlet (tubing $8,1 / 8$ i.d.), and a port (tubing 7, 1/16 i.d.) for introducing $\mathrm{KBH}_{4}$ solution. The gaseous arsines generated by hydride generation or by sediment culture in the headspace were purged with helium in the cotton column immersed in liquid nitrogen. The boiling points for arsine, methylarsine, dimethylarsine, and trimethylarsine are $-55,2,36$, and $52{ }^{\circ} \mathrm{C}$, respectively, ${ }^{25}$ and therefore, these arsenic species can be cryogenically trapped on the cotton column.

An incubation vessel (chamber 7 in Fig. 1) was constructed to allow for both sediment incubation and direct analysis of the headspace for volatile arsenic species. The incubation chamber was made of Teflon and had a total volume of $113 \mathrm{~mL}$, with an internal diameter of $4 \mathrm{~cm}$ and inside height of $9 \mathrm{~cm}$. The outer diameter was $6 \mathrm{~cm}$, and the outside height was $10 \mathrm{~cm}$. The vessel was leak-proof with the use of a rubber O-ring along with the Teflon lid. A gas inlet and an outlet, each fitted with a switch, were inserted through the lid. Both the gas inlet and outlet were turned off during the incubation process. They were switched on during the purge and trap step. The picture of the chamber design was also shown in detail in the author's previous paper. ${ }^{22}$

\subsection{Sampling}

The sediment samples were collected from one lake in Yunnan Province, China. The lake, 31 square kilometres large, was a scenic spot and supplied drinking water for three neighbouring cities. Because it was polluted by wastewater with a high concentration of arsenic in 2008, a high level of arsenic was found in both the water (around $150 \mu \mathrm{g} \mathrm{L}^{-1} \mathrm{As}$ ) and sediment of the lake (around $60 \mu \mathrm{g} \mathrm{g}^{-1} \mathrm{As}$ ). More than $1 \mathrm{~kg}$ of sediment was scratched from the bottom of the lake. The sediment was put into a polyethylene self-seal bag. The air in the bag was then squeezed out. The sample was stored in a cooler during the process of transportation to preserve the original components in the 
sediment. The water content of the sediment was high (59\%). The debris in the sediment was removed before incubation and analysis.

\section{Results and discussion}

\subsection{Separation and detection of volatile arsenic species}

Usually, direct analysis of gaseous arsenic species released from real environmental samples is challenging, especially when the amounts of gaseous arsenic species are very minor. However, detection of these minute amounts of volatile arsenic species has always been regarded as a key step for understanding the biotransformation of arsenic in the environment. Gaseous arsenic species released from environmental samples are difficult to capture and separate by most commercially available instruments. Even when pretreatment techniques such as solid phase microextraction (SPME) were applied before sample analysis, the sensitivity of GC-MS for volatile arsenic speciation was not high enough for most real sample analysis. To meet the requirement of high sensitivity, Yuan and $\mathrm{Le}^{15,22}$ designed a hyphenated GC-ICP-MS system which enabled direct speciation and detection of trace amounts of volatile arsenic species released from a bacterial culture medium. From our experience, it is difficult to separate arsenic species by any commercially available GC column, because a cryogenic trap technique has to be used to capture the volatile arsenic species onto the separation column before analysis. Purging after trapping always results in a sudden increase of system pressure as the column is warmed up during the analytical process, which can easily cause leaking of gaseous arsenicals and plasma shutdown. This major drawback complicates the analytical procedure for volatile arsenic species. On the other hand, the employment of commercial GC and ICPMS also results in a large increase in investment costs and running fees, which might not be affordable for many laboratories. Arsines can be trapped by a "U" shaped tube immersed in liquid nitrogen and separated when the U-tube is warmed up. ${ }^{2,26,27}$ These previous reports enable us to develop some simple systems for volatile arsenic speciation by using a cryogenic trapping technique. To lower the cost and simplify the operation procedure, we present in this work a new analytical method for volatile arsenic species. The schematic diagram of the analytical system is shown in Fig. 1. A short packed cotton column was used for separation of volatile arsenic species in our experiment. As a natural fiber with amino groups, cotton was investigated for separation of volatile arsenicals in our experiment. $1 \mathrm{~g}$ cotton without any further treatment was packed into the PTFE column (60 $\mathrm{cm}$ length, $20 \mathrm{~cm}$ packed with cotton, $4 \mathrm{~mm}$ i.d.). One end of the column was connected to the standard generation vessel, while the other was connected to the three way connection where the analytes were carried into the AFS atomizer by a mixture of carrier gases ( $\mathrm{Ar}$ and $\mathrm{He}$ ). When the gaseous arsenic compounds were generated in the chamber, the He carrier gas carried them into the cold trap chamber and they became trapped in the cotton column which was immersed in liquid nitrogen. After trapping for five minutes, the cotton column was taken out of the liquid nitrogen and was transferred into another empty chamber. The chamber was designed by adiabatic structure. A cap which was made of foam was used to keep the temperature stable. As the

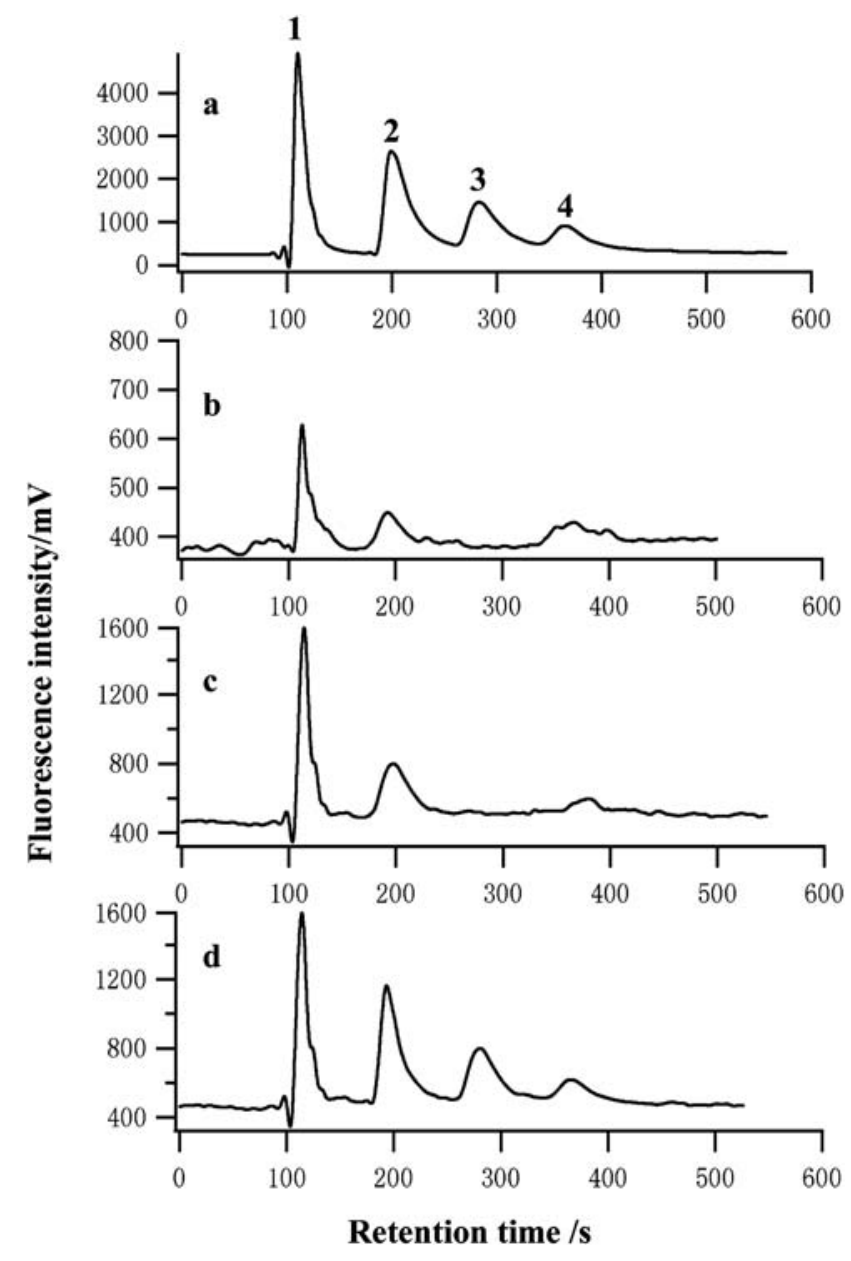

Fig. 2 Volatile arsenic species were separated and quantified by the packed cotton column and atomic fluorescence spectrometer. a: standards of $\mathrm{AsH}_{3}, \mathrm{CH}_{3} \mathrm{AsH}_{2},\left(\mathrm{CH}_{3}\right)_{2} \mathrm{AsH},\left(\mathrm{CH}_{3}\right)_{3} \mathrm{As}, 2.0 \mathrm{ng}$ respectively; b: sediment; c: sediment spiked with arsenate; d: sediment spiked with gaseous arsenic species; Peak 1, $\mathrm{AsH}_{3}$; Peak 2, $\mathrm{CH}_{3} \mathrm{AsH}_{2}$; Peak 3, $\left(\mathrm{CH}_{3}\right)_{2} \mathrm{AsH}$; Peak 4, $\left(\mathrm{CH}_{3}\right)_{3}$ As.

cold cotton column was slowly warmed up, the trapped arsenic species eventually evaporated and were further separated by the cotton column (Fig. 2 (a)). The volatile arsenic standards were generated in the reaction vessel (part 7 in Fig. 1), carried by helium gas to the separation system (parts 8, 9, and 10 in Fig. 1), and finally introduced into the atomic fluorescence detector (part 5 in Fig. 1).

\subsection{Effect of cotton on the separation of volatile arsenic species}

It was found that the cotton packed in the column played a very important role in the separation of volatile arsenic species. Although the boiling points of the volatile arsenicals are different, it is not very easy to separate the trapped volatile arsenicals chromatographically only by temperature control. When using the exact procedure described in 3.1 with an empty PTFE column without cotton, one overlapped peak was measured (Fig. 3 (a)). The results indicate that the different arsenic species could not be baseline separated only by cold trapping and temperature ramping. Fig. 3 (b) shows that even 


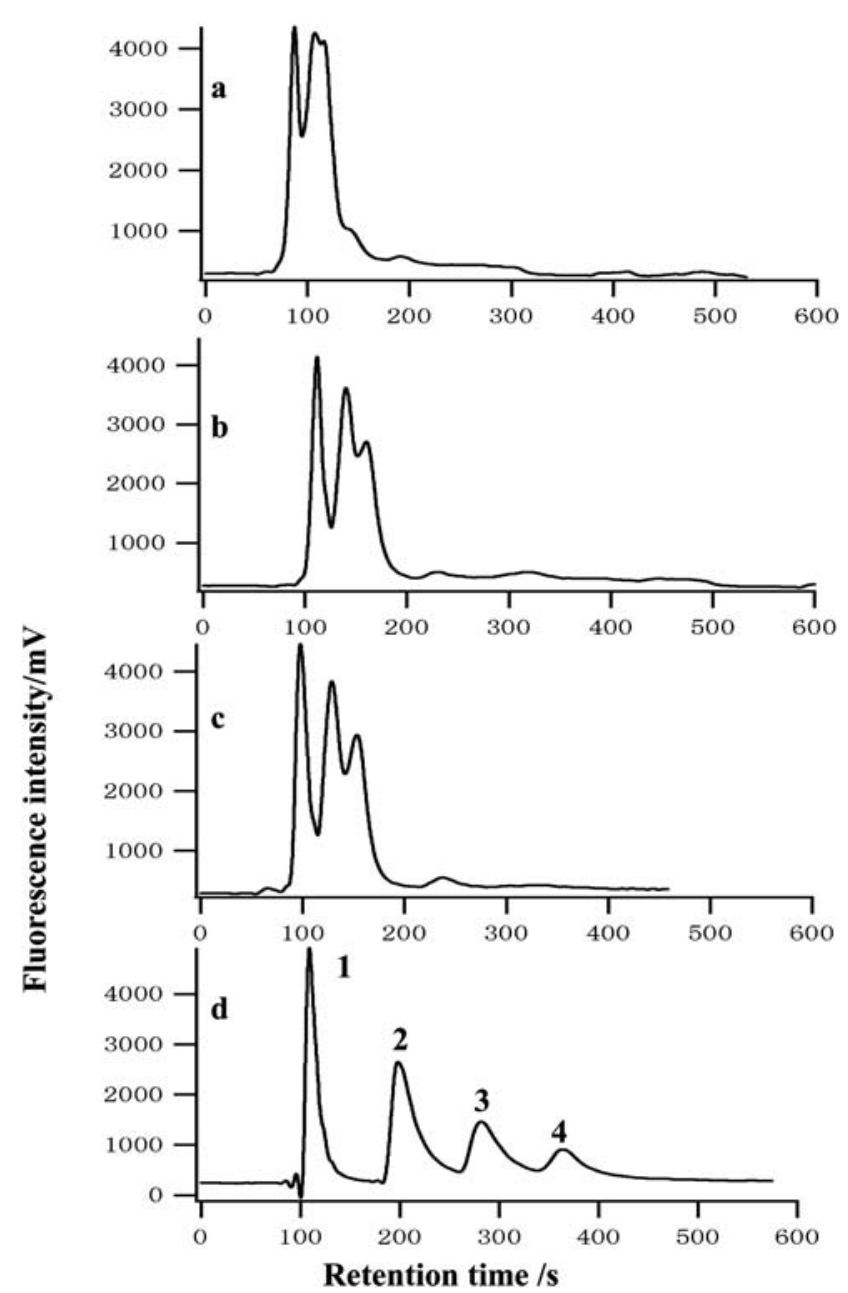

Fig. 3 Separation of gaseous arsenic species by a cotton column, a: without cotton, room temperature; $b$ : without cotton, cold separation; $\mathrm{c}$ : with cotton, room temperature; d: with cotton, cold separation; peak 1 , $\mathrm{AsH}_{3}$; peak 2, $\mathrm{CH}_{3} \mathrm{AsH}_{2}$; peak 3, $\left(\mathrm{CH}_{3}\right)_{2} \mathrm{AsH}$; peak 4, $\left(\mathrm{CH}_{3}\right)_{3} \mathrm{As} ; 2.0 \mathrm{ng}$ respectively.

when the empty column without cotton was transferred into the adiabatic chamber after cryogenic trapping, the arsenic species were still not separated. Nearly all of the three peaks, $\mathrm{CH}_{3} \mathrm{AsH}_{2}$, $\left(\mathrm{CH}_{3}\right)_{2} \mathrm{AsH}$ and $\left(\mathrm{CH}_{3}\right)_{3} \mathrm{As}$ were overlapped. Fig. 3 (c) demonstrates that when the column was packed with the cotton, but warmed up to room temperature, the peaks of the four species were still not able to be separated. When a packed cotton column was applied and warmed up in the adiabatic chamber where the temperature increased very slowly after the cold trap, the arsenic species were successfully separated (Fig. 3 (d)). The results indicate that the volatile arsenic species can be separated by cotton with a cold trap technique. The amino groups in cotton may play an important role for separation. However, the exact mechanism of separation needs to be further investigated in the future.

To use cotton as a separation phase for volatile arsenic species has many advantages. The most attractive advantages include a cheap price, low pressure of the packed column, ease of packing and replacement. The advantages, especially the low pressure compared with other GC stationary phases or commercial GC columns used for volatile arsenic separation, facilitate the connection of packed cotton column with AFS.

\subsection{Optimization of experimental conditions}

The other experimental conditions including the flow rate of carrier gas, the cotton mass, the trapping and reaction time, which may affect the detection and separation of gaseous arsenic species, were also investigated in our experiment.

An adequate mass of cotton is required for baseline separation of arsenic species. We utilized $0.1 \mathrm{~g}, 0.5 \mathrm{~g}, 1.0 \mathrm{~g}, 1.5 \mathrm{~g}$ and $2.0 \mathrm{~g}$ cotton to pack the column. The retention time and sensitivity for the various species were different when different amounts of cotton were used. When the amount of cotton was too small it was not able to provide enough separation capacity to separate the volatile arsenic species. After optimization, we chose $1 \mathrm{~g}$ cotton to pack the column with for the best separation and highest sensitivity.

We tried 30 to $100 \mathrm{~mL} \mathrm{~min}^{-1}$ flow rates of carrier gas $(\mathrm{He})$ for separation of volatile arsenic species on the cotton column. Higher flow rates of $\mathrm{He}$ provided faster elution and shorter separation times. Even though the introduction of He did not cause any influence on the stability of the flame, too high a flow rate of carrier gas was not good for cold trapping of volatile arsenicals. The results are shown in Fig. 4. $80 \mathrm{~mL} \mathrm{~min}^{-1}$ was chosen as the optimum flow rate in our experiment.

Sufficient time is needed for both generating the standards of volatile arsenic species and for the cold trap. 1-6 min trapping and reaction time was investigated in our experiment (Fig. 5). It was found that $5 \mathrm{~min}$ was enough time for the cold trap and standards generation. A time longer than $5 \mathrm{~min}$ did not result in enhanced sensitivity and even caused a slight decrease in sensitivity. 5 min was therefore chosen as the amount of time for standards generation and trapping.

\subsection{Analytical figures of merit}

Fig. 2 (a) shows the chromatogram from the analysis of volatile arsenic species standards (2.0 ng, respectively) by the proposed method. The four arsenic species were baseline separated within $5 \mathrm{~min}$, and the detection limits for $\mathrm{AsH}_{3}, \mathrm{CH}_{3} \mathrm{AsH}_{2},\left(\mathrm{CH}_{3}\right)_{2} \mathrm{AsH}$ and $\left(\mathrm{CH}_{3}\right)_{3} \mathrm{As}$ were $2.5 \mathrm{pg}, 3.0 \mathrm{pg}, 6.5 \mathrm{pg}$ and $11 \mathrm{pg}$ respectively. The calibration curves were dynamically linear in the ranges of $25 \mathrm{pg}$ to $10 \mathrm{ng}$ for $\mathrm{AsH}_{3}, 50 \mathrm{pg}$ to $100 \mathrm{ng}$ for $\mathrm{CH}_{3} \mathrm{AsH}_{2}$ and $\left(\mathrm{CH}_{3}\right)_{2} \mathrm{AsH}$, and $100 \mathrm{pg}$ to $100 \mathrm{ng}$ for $\left(\mathrm{CH}_{3}\right)_{3} \mathrm{As}$. The RSD for five repeated analyses of a $2.0 \mathrm{ng}$ volatile arsenic species mixture was $<5 \%$. The equation of the calibration curve, detection limits and correlation coefficient $\left(R^{2}\right)$ are shown in Table 1 . The stability and reproducibility of the analytical method are crucial for real sample analysis. Three repetitions of standards were analyzed by the same packed column, and good reproducibility was achieved (Fig. 6).

\subsection{Analysis of volatile arsenic species generated from sediment}

To validate the method for real sample analysis, $20 \mathrm{~g}$ sediment was placed into the incubation vessels. The sediment sample was incubated at $37{ }^{\circ} \mathrm{C}$ for $24 \mathrm{~h}$. The gas in the headspace was then carried into the packed cotton column immersed in liquid 


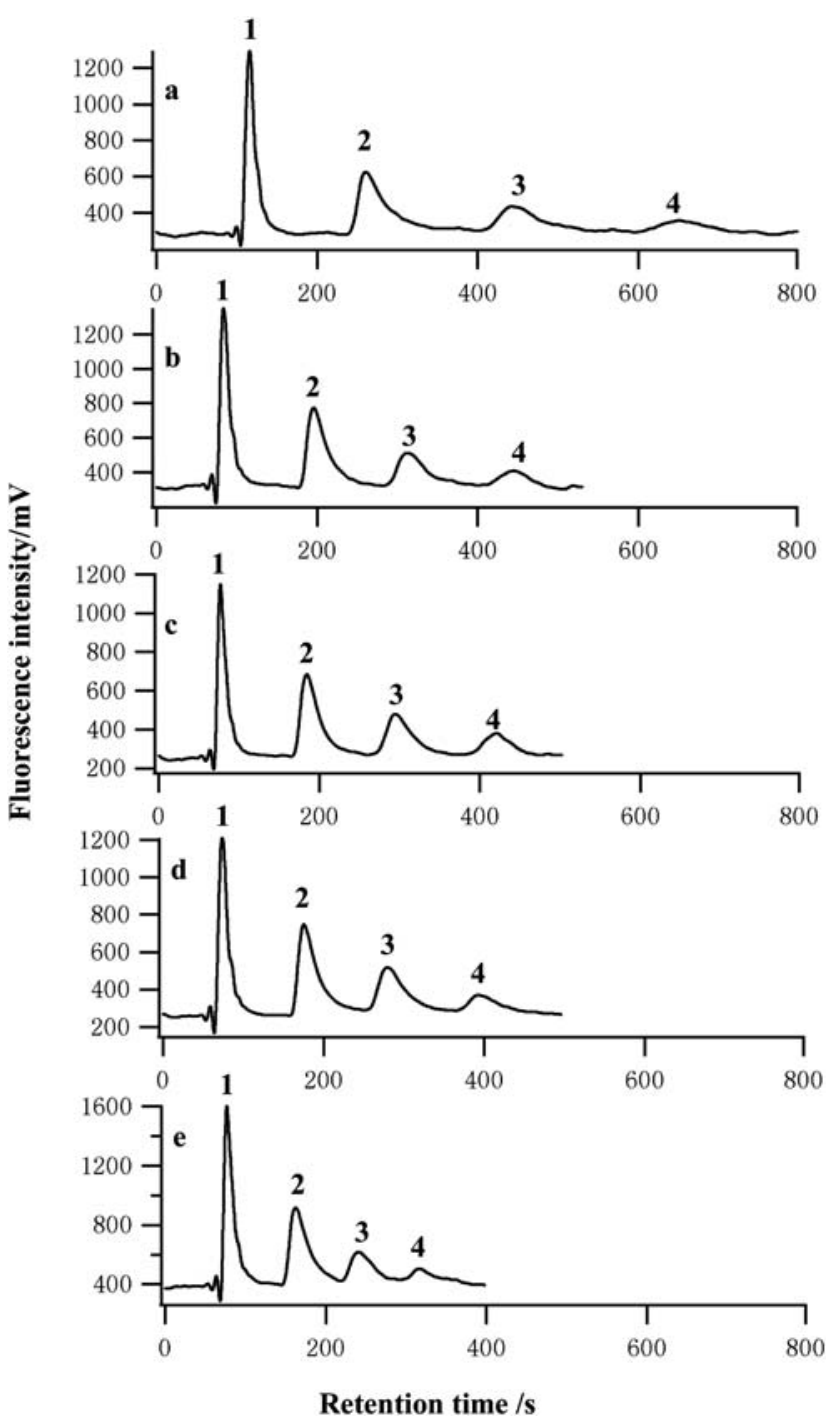

Fig. 4 Effect of carrier gas on separation and detection. a: $30 \mathrm{~mL} \mathrm{~min} \mathrm{mi}^{-1}$; b: $50 \mathrm{~mL} \mathrm{~min}^{-1}$; c: $60 \mathrm{~mL} \mathrm{~min}^{-1}$; d: $80 \mathrm{~mL} \mathrm{~min}^{-1}$; e: $100 \mathrm{~mL} \mathrm{~min}^{-1}$; peak 1 , $\mathrm{AsH}_{3}$; peak 2, $\mathrm{CH}_{3} \mathrm{AsH}_{2}$; peak 3, $\left(\mathrm{CH}_{3}\right)_{2} \mathrm{AsH}$; peak 4, $\left(\mathrm{CH}_{3}\right)_{3} \mathrm{As} ; 0.5 \mathrm{ng}$ respectively.

nitrogen by He (part 10 in Fig. 1). Fig. 2 (b) shows that gaseous arsenic species released from the sediment culture were detected by the established coupling system. Both the hydride derivative of arsenic $\left(\mathrm{AsH}_{3}\right)$ and methylated derivatives of arsenic $\left(\mathrm{CH}_{3} \mathrm{AsH}_{2}\right.$ and $\left.\left(\mathrm{CH}_{3}\right)_{3} \mathrm{As}\right)$ were directly determined. Dimethylarsine was not detectable in the sample. To confirm that the gaseous arsenic compounds were generated from the sediment, the standard solution of arsenate $\left(\mathrm{As}^{\mathrm{v}}\right)\left(1.0 \mu \mathrm{g} \mathrm{mL}^{-1}, 1 \mathrm{~mL}\right)$ was spiked into the sediment and incubated at $37{ }^{\circ} \mathrm{C}$ for $24 \mathrm{~h}$. The incubated sample was thereafter also measured using the established method. The observable enhancement of peaks $\left(\mathrm{AsH}_{3}\right.$ and $\mathrm{CH}_{3} \mathrm{AsH}_{2}$ ) and calibration demonstrated that $\mathrm{As}^{\mathrm{V}}$ was partly transformed into gaseous arsenic species (Fig. 2 (c)). Although the proportion of transformation from $\mathrm{As}^{\mathrm{v}}$ to gaseous arsenicals was small (Table 2), the amounts of gaseous arsines released into the gas phase from the sites polluted by arsenic would be considerable and hazardous if both a high level of arsenic and
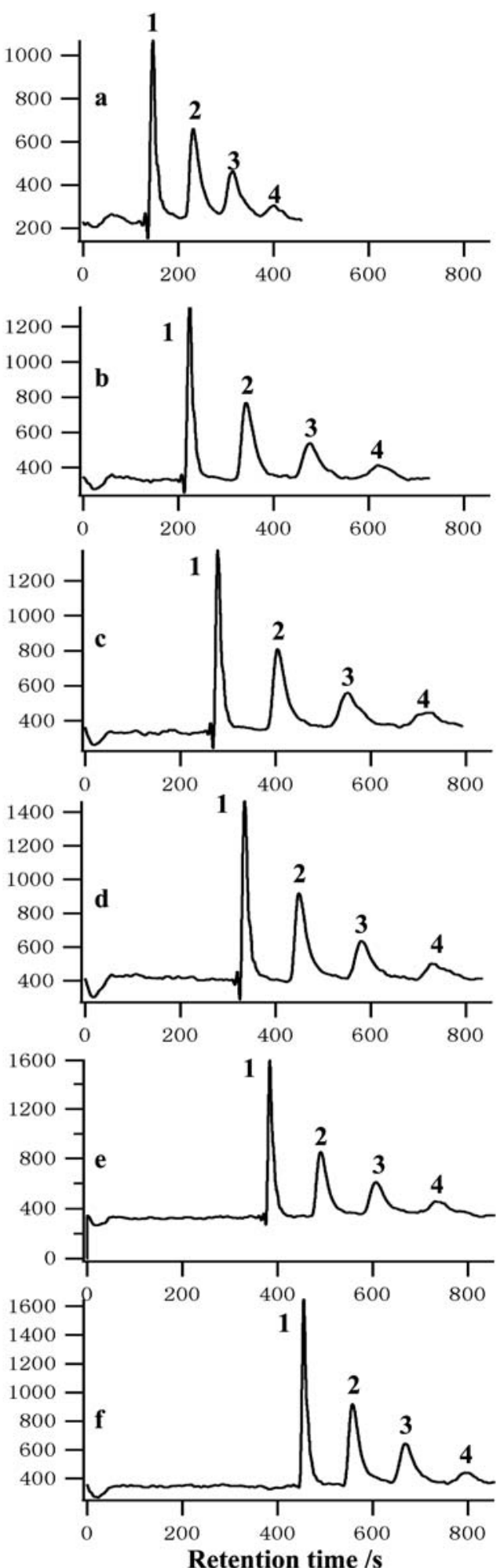

Fig. 5 Effect of trap and reaction time. a: $1 \mathrm{~min}$; b: $2 \mathrm{~min}$; c: $3 \mathrm{~min}$; $\mathrm{d}$ 4 min; e: 5 min; f: $6 \mathrm{~min}$; peak 1, $\mathrm{AsH}_{3}$; peak 2, $\mathrm{CH}_{3} \mathrm{AsH}_{2}$; peak 3, $\left(\mathrm{CH}_{3}\right)_{2} \mathrm{AsH}$; peak $4,\left(\mathrm{CH}_{3}\right)_{3} \mathrm{As} ; 0.5 \mathrm{ng}$ respectively.

microbes with arsenic resistance genes were present. To further identify the species released from the sample, volatile arsenic species standards generated by the reaction were also spiked (introduced) into the incubation vessel and captured together 
Table 1 Analytical characteristics of the system

\begin{tabular}{|c|c|c|c|c|}
\hline $\begin{array}{l}\text { Volatile } \\
\text { arsenic } \\
\text { species }\end{array}$ & $\begin{array}{l}\text { Regression } \\
\text { equation }^{a}\end{array}$ & $\begin{array}{l}\text { Correlation } \\
\text { coefficient } \\
\left(R^{2}\right)\end{array}$ & $\begin{array}{l}\text { Detection } \\
\operatorname{limit}^{b} / p g\end{array}$ & $\begin{array}{l}\text { RSD } \\
(\%, n=5)\end{array}$ \\
\hline AsH & $A=2823.3 C+238.2$ & 0.9989 & 2.5 & 3.2 \\
\hline $\mathrm{CH}_{3} \mathrm{AsH}_{2}$ & $A=2804.0 C-50.0$ & 0.9996 & 3.0 & 4.9 \\
\hline$\left(\mathrm{CH}_{3}\right)_{2} \mathrm{AsH}$ & $A=1969.5 C-161.8$ & 0.9992 & 6.5 & 3.7 \\
\hline$\left(\mathrm{CH}_{3}\right)_{3} \mathrm{As}$ & $A=1098.7 C-228.1$ & 0.9993 & 11 & 4.5 \\
\hline
\end{tabular}

${ }^{a} C$ means the mass amount of volatile arsenic; $A$ means the intensity of produced fluorescence. ${ }^{b}$ Detection limit (DL) was defined as the amount of arsenic which produced a signal intensity equal to three times the standard deviation of the baseline noise (38).

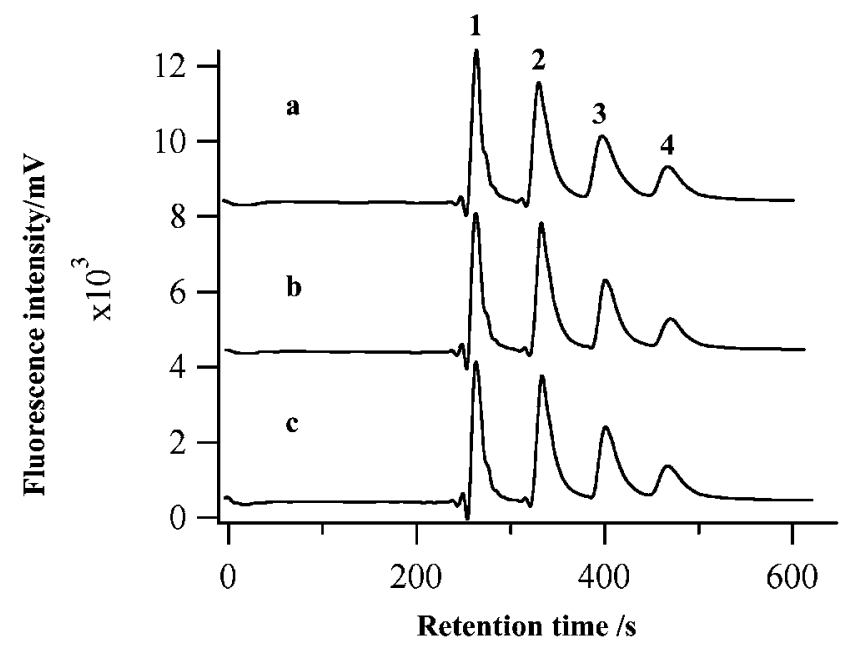

Fig. 6 Repeatability of analysis. a, b, c: three replicates; peak 1, $\mathrm{AsH}_{3}$; peak 2, $\mathrm{CH}_{3} \mathrm{AsH}_{2}$; peak 3, $\left(\mathrm{CH}_{3}\right)_{2} \mathrm{AsH}$; peak 4, $\left(\mathrm{CH}_{3}\right)_{3} \mathrm{As} ; 2.0 \mathrm{ng}$ respectively.

with the volatile arsenic species released from the sediment on the packed cotton column. After trapping, these species were separated by the proposed system. The chromatogram (Fig. 2 (d)) illustrates that the retention time of volatile arsenic standards and volatile arsenicals released from the sediment matched very well. The enhancement of peaks in Fig. 2 (d) (compared with the chromatogram of sediment sample in Fig. 2 (b)) also confirmed that volatile arsenic species were generated by the sediment sample. The amounts of volatile arsenic species generated from the sediment samples, the transformation proportion of $\mathrm{As}^{\mathrm{v}}$ into volatile species and the recoveries of the spiked volatile arsenic species were all calculated in our experiment. The quantification results are shown in Table 2. The aim to apply this established method here was only to demonstrate its feasibility, not to study the mechanism of arsenic transformation in sediment. Certainly, the amounts of volatile arsenic species generated or the transformation proportion of $\mathrm{As}^{\mathrm{v}}$ in sediment are affected by other variables and conditions. The mechanism and conditions need to be further studied in the future. The results from our experiment indicate that the method is sensitive and practical enough for real sample analysis, which will be very helpful for the study of the transformation and transportation of arsenic between different phases in the environment.
Table 2 Analysis of volatile arsenic species released from the sediment of a lake polluted by arsenic (ng, $n=3$ )

\begin{tabular}{|c|c|c|c|c|}
\hline \multirow[b]{2}{*}{ Sample } & \multicolumn{4}{|c|}{ Volatile arsenic species } \\
\hline & $\mathrm{AsH}_{3}$ & $\mathrm{CH}_{3} \mathrm{AsH}_{2}$ & $\left(\mathrm{CH}_{3}\right)_{2} \mathrm{AsH}$ & $\left(\mathrm{CH}_{3}\right)_{3} \mathrm{As}$ \\
\hline $\begin{array}{l}\text { Sediment } \\
\qquad(\mathrm{C} 1)^{a}\end{array}$ & $0.22 \pm 0.05$ & $0.16 \pm 0.02$ & ND & $0.34 \pm 0.04$ \\
\hline $\begin{array}{l}\text { Sediment } \\
\text { spiked with } \\
\operatorname{As}^{\mathrm{v}}(\mathrm{C} 2)^{b}\end{array}$ & $0.57 \pm 0.08$ & $0.29 \pm 0.04$ & ND & $0.45 \pm 0.08$ \\
\hline $\begin{array}{l}\text { Volatile arsenic } \\
\text { species spiked } \\
(\mathrm{C} 3)^{c}\end{array}$ & 0.30 & 0.30 & 0.50 & 0.50 \\
\hline $\begin{array}{l}\text { Sediment spiked } \\
\text { with volatile } \\
\text { arsenic species } \\
\text { (C4) }\end{array}$ & $0.59 \pm 0.05$ & $0.43 \pm 0.06$ & $0.57 \pm 0.05$ & $0.85 \pm 0.07$ \\
\hline $\begin{array}{l}\text { Transformation } \\
\text { proportion } \\
(\%)^{d}\end{array}$ & 0.035 & 0.013 & - & 0.011 \\
\hline $\begin{array}{l}\text { Recovery of the } \\
\text { spiked volatile } \\
\text { arsenic species } \\
(\%)^{e}\end{array}$ & 123 & 90 & 114 & 102 \\
\hline \multicolumn{5}{|c|}{$\begin{array}{l}{ }^{a} 20 \mathrm{~g} \text { of sediment was incubated at } 37{ }^{\circ} \mathrm{C} \text { for } 24 \mathrm{~h} \text {, and then the } \\
\text { headspace was trapped and analyzed. }{ }^{b} \text { The sediment was spiked with } \\
1000 \mathrm{ng} \mathrm{As} \text { and then was incubated. }{ }^{c} \text { After the sediment sample was } \\
\text { incubated, suitable amounts of volatile arsenic species standards, } \\
\text { generated by hydrogen reaction in the reaction vessel, were added into } \\
\text { the incubation vessel, and then trapped and analyzed together with the } \\
\text { volatile arsenicals in the headspace produced by sediment. } \\
{ }^{d} \text { Transformation proportion }=(\mathrm{C} 2-\mathrm{C} 1) / 1000 \times 100 \%{ }^{e} \text { Recovery }= \\
(\mathrm{C} 4-\mathrm{C} 1) / \mathrm{C} 3 \times 100 \% \text {. }\end{array}$} \\
\hline
\end{tabular}

\section{Conclusions}

In summary, volatile arsenic species were separated by a packed cotton column and sensitively detected by AFS. This method facilitates and simplifies the speciation and detection procedure of volatile arsenic species. The instrumental and running fee is low, which in turn can be affordable for most laboratories. The method was validated by analyzing the volatile arsenic species released from the sediment of a polluted lake. The results demonstrate that the new, sensitive, simple and practical method is applicable for real sample analysis. This work is very helpful for further understanding the biogeocycling of arsenic in the environment.

\section{Acknowledgements}

This work was kindly co-funded by the National Natural Science Foundation of China (20807014), the Program for New Century Excellent Talents in University (NCET-10-0341), the Specialized Research Fund for the Doctoral Program of Higher Education (200800791013), the State Key Laboratory of Environmental Chemistry and Ecotoxicology, the Research Center for EcoEnvironmental Sciences, the Chinese Academy of Sciences (KF2008-01), the Fundamental Research Funds for the Central Universities (10ZG01) and the Natural Science Foundation of Hebei Province (B2010001676). The authors thank Professor X. Chris Le from the University of Alberta, Canada for donating arsenic standards. 


\section{References}

1 H. Bhattacharjee and B. P. Rosen, Microbiology Monographs, 2007, 6, 371-406.

2 R. S. Braman and C. C. Foreback, Science, 1973, 182(4118), 1247-1249.

3 J. Meyer, K. Michalke, T. Kouril and R. Hensel, Syst. Appl. Microbiol., 2008, 31(2), 81-87.

4 D. Mohapatra, D. Mishra, G. R. Chaudhury and R. P. Das, Soil Sediment Contam., 2008, 17(3), 301-311.

5 M. Urík, S. Cernansky, J. Sevc, A. Simonovicova and P. Littera, Water, Air, Soil Pollut., 2007, 186(1-4), 337-342.

6 R. S. Oremland and J. F. Stolz, Science, 2003, 300, 939-44.

7 J. F. Stolz, P. Basu, J. M. Santini and R. S. Oremland, Annu. Rev. Microbiol., 2006, 60, 107-30.

8 S. M. A. Islam, K. Fukushi, K. Yamamoto and G. C. Saha, Arch Environ. Contam. Toxicol., 2007, 52(3), 332-338.

9 X. M. Guo, R. E. Sturgeon, Z. Mester and G. J. Gardner, J. Anal. At. Spectrom., 2005, 20(8), 702-708.

10 B. B. Edvantoro, R. Naidu, M. Megharaj, G. Merrington and I. Singleton, Appl. Soil Ecol., 2004, 25(3), 207-217.

11 B. Planer-Friedrich, C. Lehr, J. Matschullat, B. J. Merkel, D. K. Nordstrom and M. W. Sandstrom, Geochim. Cosmochim. Acta, 2006, 70(10), 2480-2491.

12 R. S. Oremland, T. R. Kulp, J. S. Blum, S. E. Hoeft, S. Baesman, L. G. Miller and J. F. S1tolz, Science, 2005, 308, 1305-1308.

13 D. Malasarn, C. W. Saltikov, K. M. Campbell, J. M. Santini, J. G. Hering and D. K. Newman, Science, 2004, 306, 455.
14 J. Qin, B. P. Rosen, Y. Zhang, G. Wang, S. Franke and C. Rensing, Proc. Natl. Acad. Sci. U. S. A., 2006, 103, 2075-80.

15 J. Qin, C. R. Lehrb, C. G. Yuan, X. C. Le, T. R. McDermott and B. P. Rosen, Proc. Natl. Acad. Sci. U. S. A., 2009, 106(13), 5213-5217.

16 J. Meyer, A. Schmidt, K. Michalke and R. Hensel, Syst. Appl. Microbiol., 2007, 30(3), 229-238.

17 L. Helsen, Environ. Pollut., 2005, 137(2), 305-315.

18 R. A. Diaz-Bone, M. Hollmann, O. Wuerfel and D. Pieper, J. Anal. At. Spectrom., 2009, 24(6), 808-814.

19 J. Kösters, R. A. Diaz-Bone, B. Planer-Friedrich, B. Rothweiler and A. V. Hirner, J. Mol. Struct., 2003, 661, 347-356.

20 A. Mestrot, M. K. Uroic, T. Plantevin, M. R. Islam, E. M. Krupp, J. Feldmann and A. A. Meharg, Environ. Sci. Technol., 2009, 43(21), 8270-8275.

21 M. K. Uroic, E. M. Krupp, C. Johnson and J. Feldmann, J. Environ. Monit., 2009, 11, 2222-2230.

22 C. G. Yuan, X. Lu, J. Qin, B. P. Rosen and X. C. Le, Environ. Sci. Technol., 2008, 42(9), 3201-3206.

23 X. C. Le, X. Lu, M. Ma, W. R. Cullen, V. Aposhian and B. Zheng, Anal. Chem., 2000, 72, 5172-5177.

24 X. Lu, L. L. Arnold, S. M. Cohen, W. R. Cullen and X. C. Le, Anal. Chem., 2003, 75, 6463-6468.

25 M. Pantsar-Kallio and A. Korpela, Anal. Chim. Acta, 2000, 410, 65-70.

26 A. G. Howard and C. Salou, J. Anal. At. Spectrom., 1998, 13, 683-686.

27 J. C. Ng, D. Johnson, P. Imray, B. Chiswell and M. R. Moore, Analyst, 1998, 123, 929-933. 